\title{
Patients are expecting to learn more: $A$ longitudinal study of patients with heart failure undergoing device implantation
}

Brynja Ingadottir, Ingela Thylén, Kerstin Ulin and Tiny Jaarsma

The self-archived postprint version of this journal article is available at Linköping University Institutional Repository (DiVA):

http://urn.kb.se/resolve?urn=urn:nbn:se:liu:diva-167282

N.B.: When citing this work, cite the original publication.

Ingadottir, B., Thylén, I., Ulin, K., Jaarsma, T., (2020), Patients are expecting to learn more: A longitudinal study of patients with heart failure undergoing device implantation, Patient Education and Counseling, 103(7), 1382-1389. https://doi.org/10.1016/j.pec.2020.02.023

Original publication available at:

https://doi.org/10.1016/j.pec.2020.02.023

Copyright: Elsevier

http://www.elsevier.com/

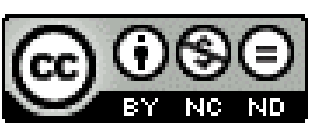




\section{Title}

Patients are expecting to learn more: a longitudinal study of patients with heart failure undergoing device implantation

\section{Authors}

Brynja Ingadottir ${ }^{1,2}$

Ingela Thylén ${ }^{3,4}$

Kerstin Ulin ${ }^{5,6}$

Tiny Jaarsma ${ }^{7}$

${ }^{1}$ Faculty of Nursing, School of Health Sciences, University of Iceland, Reykjavik, Iceland

${ }^{2}$ Surgical Services, Landspitali University Hospital, Reykjavik, Iceland

${ }^{3}$ Department of Cardiology, Linköping University Hospital, Linköping, Sweden

${ }^{4}$ Department of Medical and Health Sciences, Linköping University, Linköping, Sweden

${ }^{5}$ Institute of Health and Care Sciences, Sahlgrenska Academy, University of Gothenburg, Gothenburg, Sweden

${ }^{6}$ Department of Medicine, Geriatrics and Emergency Care, Sahlgrenska University Hospital, Gothenburg, Sweden

${ }^{7}$ Division of Nursing Science, Department of Social and Welfare Studies, Linköping University, Linköping, Sweden

\section{Corresponding author at:}

Dr. Brynja Ingadottir

Faculty of Nursing, School of Health Sciences, University of Iceland

Eiriksgata 34, 101 Reykjavik, Iceland

Tel: + 3545254913

E-mail: brynjain@hi.is 


\section{ABSTRACT}

Objective: To explore patients with heart failure expectations and experiences of education in relation to device implantation.

Methods: In this longitudinal study, patients with heart failure at six Swedish and Icelandic hospitals answered instruments about their knowledge expectations, before the device implantation, and about the knowledge they had received at two weeks, six months and 12 months after the procedure. Predictors for fulfillment of knowledge expectations were assessed with linear mixed model analysis.

Results: Patients (N=133, mean age $69.8( \pm 9.7)$ years, $80 \%$ men) had high knowledge expectations, which for $83 \%$ of them were unfulfilled. Predictors for fulfillment of knowledge expectations were access to knowledge from healthcare professionals ( $\beta$ 0.74, 95\% CI: 0.42 to 1.10), educational level ( $\beta-0.30,95 \%$ CI: -0.52 to -0.07 ) and knowledge expectations ( $\beta-1.03$, $95 \%$ CI: -1.30 to -0.80$)$. Healthcare professionals were the main information source $(89 \%), 74 \%$ of patients received written information, and 19\% had used the Internet.

Conclusions: Patients receive less knowledge than they expect, and individual factors and communication with healthcare professionals are related to their experience. Face-to-face is the most common method of delivering education.

Practice implications: Healthcare professionals should assess patients' expectations for information and consider implementing more diversity in their educational practices.

Key words: Cardiac Resynchronization Therapy Device; Heart Failure; Patient Education as Topic; Patient Reported Outcome Measures: Patient Satisfaction 


\section{Introduction I moved the first paragraph up here}

Heart failure (HF) is a serious chronic and common condition, affecting around $1-2 \%$ of the population of Western countries [1]. As the disease progresses patients experience common symptoms such as fatigue, anxiety and depression, problems with physical functioning, all of which negatively affect their quality of life, morbidity and mortality [2]. Cardiac resynchronization therapy (CRT) is a medical management of HF symptoms which helps selected patients with HF who have a systolic dysfunction and ventricular dyssynchrony. The treatment consists of implantation of a cardiac device, a so-called biventricular pacemaker, either with (CRT-D) or without (CRT-P) a defibrillator function. The treatment has been available to patients with HF for 20 years and has been proved to reduce mortality and morbidity and improve quality of life through improved cardiac synchronization [3]. The treatment requires a minimal surgical procedure although it can be complicated due to the complex anatomy of the coronary vein [4] and requires a short hospitalization ( $<48$ hours).

The importance of patient education is widely recognized within nursing and it is both a professional and ethical duty of nurses $[5,6]$ to provide it, as well as a statutory right of patients to receive it in some countries, for example Sweden and Iceland [7,8]. Patient education has developed in various ways in the last 50 years or so. The role of both the patient and the provider has shifted. For the patient the role has shifted from being a passive recipient of care to being a participant in shared decision-making [9]. Instead of providing selective information, based on healthcare providers' own preferences, they nowadays need to address the patient's perspective and respond to patients' self-identified information needs [6,9]. For patients to be able to take on this new active role of making informed choices and decisions regarding their own health [6] they need both knowledge and confidence, the attributes of empowerment, which have been recognized as imperative for sustainable health systems [10]. Empowerment can be supported by providing information to patients. Within the theoretical perspective of empowering patient education (EPE), patient education is a nursing intervention to improve patients' knowledge level. It is assumed that the closer received knowledge, referring to when a patient has received available information and made it a part of her/his own knowledge base, is to knowledge expectations, that is, when knowledge expectations are fulfilled, the stronger the patients' potential for empowerment [11]. To manage their health, patients need multidimensional 
knowledge, not only about their disease and its treatment or its effect on daily functions but also its effects on feelings, on the ethical aspects of care, on available social support and on the financial implications of care [11]. Previous studies indicate that patients undergoing surgery have high knowledge expectations but their expectations are insufficiently fulfilled [12-15]. However, technological and bio-physiological aspects of care seem to be most expected by patients and best addressed by healthcare professionals [16,17] but expectations on experiential, ethical, social and financial issues are the least fulfilled [12-14]. The use of a variety of communication and information technologies has been encouraged [6] as effective patient education and can be promoted with interactivity, multi-sessions, the use of multiple media and modes of delivery, as well as by providing individualized care [18-20] or person-centered care [21].

Patient education for surgical patients is important in order to reduce pre-operative anxiety, and support post-operative self-care and recovery. However, decision-making around CRT is often complex and should be part of a larger discussion about the prognosis and should include an individual risk-benefit ratio. Current guidelines specifically recommend that informed, shared decision-making should be considered as integral before the implantation and aligned with the patient's values, goals, and preferences [22]. Therefore, the objective of this study was to explore the educational expectations and experiences of patients with heart failure in relation to their treatment for HF with CRT up to one year after the implantation of the device.

\section{Methods}

\subsection{Design}

This was a longitudinal survey study with data collected at four time points: at baseline before the CRT implantation procedure, two weeks, six months and 12 months following the procedure.

\subsection{Setting}

Data was collected by research nurses between May 2012 and December 2015, in cardiology departments at five Swedish and one Icelandic hospital, consisting of two regional hospitals and four university hospitals. 
A similar procedure applied to patients at the participating centers. After receiving information from their cardiologists and accepting the treatment, the patients were put on a waiting list for the procedure. When the procedure had been scheduled they were sent written information in the post with their admission information, they were usually admitted at the day of the CRT implantation and discharged the following day. The cardiologists performing the procedure in Iceland were trained in Sweden and patients there received treatment comparable to that in Sweden.

\subsection{Participants}

All consecutive patients with HF, scheduled for a first time, elective CRT device implantation, were invited to participate in the study. Patients were included if they were aged 18 years or older, had no cognitive impairment diagnosed and documented in their medical records and if they were able to understand Swedish/Icelandic. Patients were excluded if they were receiving an upgrade of any type of cardiac device. Patients scheduled for the CRT procedure were screened for eligibility by research nurses at each center. Those fulfilling the inclusion criteria were sent an invitation letter, a consent form, a pre-stamped envelope and the first questionnaire (including the Knowledge Expectations of hospital patients (KEhp) Scale) when a date for the procedure had been planned. Patients willing to participate in the study returned a signed consent form and a filled-out questionnaire to the researchers. A study coordinator was in contact with the research nurses at each center who confirmed the date of the procedure or any delays or changes in planning. The coordinator then mailed the remaining questionnaires in due time. Patients completed the questionnaires themselves or with an assistance from their relatives.

\subsection{Measurements}

Data was collected with four previously validated instruments:

The Knowledge Expectations of hospital patients (KEhp) Scale, was mailed to patients before the CRT implantation procedure, and the Received Knowledge of hospital patients (RKhp) Scale [11] was mailed to patients at two weeks, six months and 12 months after the CRT implantation procedure. These are two parallel instruments, each consisting of 40 similar items (preceded with 'I expect knowledge on...' in KEhp and 'I received knowledge on...' in RKhp) which are divided into six subscales i.e., bio-physiological (e.g. on disease, treatment, possible complications), 
functional (e.g. on daily activities such as diet, rest, mobility, hygiene), experiential (e.g. emotions, previous hospital experience), ethical (rights and duties of patients and health care providers), social (available support), and financial (costs of treatment and rights in the social security system). Responses are ranked on a four-point Likert-like scale ( 1 = fully disagree, $4=$ fully agree, $0=$ not applicable). A mean score is calculated for a total scale and each subscale with the possible range of 1-4 where lower scores reflect lower expectations and less received knowledge. The difference between the two scales (hereafter referred to as fulfillment of knowledge expectations) is calculated by subtracting the score of the KEhp scale from the RKhp score (RKhp-KEhp). Thus, a difference of 0 between the scores represents fully met knowledge expectations, a negative score $(<0)$ represents unfulfilled expectations, and a positive score $(>0)$ indicates that more knowledge was received than expected. The two instruments have previously been tested; their content has been validated, and they have shown good internal consistency in their original Finnish versions [11,12] and in an international study [14]. The Cronbach's alphas of the instruments in this study were 0.98 for KEhp (for subscales $0.85-0.93$ ) and 0.97-0.98 for RKhp (for subscales 0.85-0.97).

The Access to Knowledge Scale (AKS) [23] was mailed to patients administered at two weeks, six months and 12 months. The AKS consists of eight statements about contact with and the sufficiency of information provided by nurses and physicians during hospitalization. The statements cover matters such as how well the medical staff and nurses could answer the patient's questions and justify their actions, keep patients and significant others up to date with carerelated matters, and provide patients with knowledge. The items in AKS are part of different theoretical components of the Good Nursing Care Scale [23]. Responses are ranked on a fourpoint Likert-like scale ( 1 = fully disagree, 4 = fully agree). A mean score is calculated for a total scale with the possible range of 1-4 where lower scores reflect lower access. Internal consistency reliability in this study was assessed with Cronbach's alpha (0.82 - 0.89).

The Patient Satisfaction Scale (PSS) was mailed to patients administered at two weeks, six months and 12 months. The PSS consists of 11 statements about satisfaction with hospital care and has a four-point response scale ( 1 = very dissatisfied, $4=$ very satisfied $)$. A mean score is calculated for a total scale with the possible range of 1-4, where lower scores reflect lower satisfaction. The psychometric properties of the PSS in different European patient populations 
have been reported to be satisfactory [24-26] and in this study, the Cronbach's alpha of the scale was $0.93-0.97$.

Demographic and background data were collected with specific questions in the questionnaire, i.e., on education, employment, including previous work experience within health care or social services and living arrangements (living alone, with others, or in an institution). Patients answered additional questions on from where they had received information about their CRT treatment, the usability of the information they had received, whether they would have liked more information before the procedure, whether they had any remaining questions or concerns, perceived support from healthcare professionals and family and friends, their satisfaction with the effect of the treatment on their health, and whether their hospital stay had been as expected. Clinical data was collected from patient records at hospital discharge concerning on the type of CRT implanted (pacemaker only or pacemaker with a defibrillator), New York Heart Association (NYHA) Functional Classification and comorbidities.

\subsection{Statistical methods}

Descriptive statistics (mean ( \pm standard deviation)), frequencies and proportions $(\%)$ were used to describe the sample characteristics and background, knowledge expectations, received knowledge, access to knowledge and patient satisfaction.

A paired t-test between knowledge expectations and received knowledge was used to examine the fulfillment of knowledge expectations at two weeks, six months and 12 months after the procedure. Fulfillment of knowledge expectations between two or more independent groups was tested with a Student t-test or one-way analysis of variance as appropriate. The relationship between fulfillment of knowledge expectations and patient satisfaction was assessed with Spearman's correlation coefficient.

Linear mixed models for repeated measures with random effect for subject were used to assess the main effects of access to information provided by nurses and physicians (AKS), demographic variables (age, sex, education, employment, including employment in healthcare/social services, living alone/with others), CRT type and satisfaction with care (PSS) on the fulfillment of knowledge expectations. A linear mixed model was chosen 
because it accounts for within-person correlations over time and varying time intervals between assessments and allows different number of assessments [27].

In all tests, the level of statistical significance was set at 0.05. SPSS version 24 (IBM Corp., Armonk, NY, USA) and R version 3.5 (R Core Team, 2018) were used for analysis.

\subsection{Ethical approval}

The study conforms to the Declaration of Helsinki [28] and the relevant ethical committees in each country approved the study (Sweden Dnr 2012/120-31, Iceland 12-029-S1).

\section{Results}

\subsection{Participants}

A total of 175 patients were eligible for inclusion and 133 patients accepted the invitation to participate in the study ( $76 \%$ response rate). Characteristics of patients who declined to participate were comparable to the sample regarding age and gender. Two weeks after the implantation, 105 participants answered the questionnaires, after six months 98 participants answered, and after 12 months, 90 participants answered the questionnaires. The non-response rate at 12 months was $32 \%$ (Figure 1).

\section{Insert Figure 1}

The participants' mean age was $69.8( \pm 9.7)$ years and $80 \%$ were men. The majority $(94 \%)$ of the participants were in NYHA class II or III before the CRT implantation and 67\% received a CRTD device. Table 1 presents the background characteristics of the participants.

\section{Insert Table 1}

\subsection{Expected and received knowledge}

Knowledge expectations were higher than received knowledge, as assessed at all time points and within each dimension, i.e., knowledge expectations were not fulfilled. Least fulfilled were the expectations within the experiential dimension but the best fulfilled expectations were within the bio-physiological, functional and financial dimensions (Figure 2). On average, $83 \%$ of patients 
did not have their knowledge expectations fulfilled. Table 2 Appendix 1 presents the values for expected and received knowledge.

\section{Insert Figure 2}

Insert Table 2

\subsection{Patients' information seeking, information sources, access to knowledge, and} remaining information needs

Patients' main source of information at baseline and during the one-year follow-up was healthcare professionals working at the heart failure out-patient clinic and the hospital. After six months, $19 \%$ of patients had received information from the Internet and 1\% had used patient organizations as an information source. Before the procedure, $50 \%$ of patients reported they had received information from brochures, in comparison with $74 \%$ after six months (Figure 3 ).

\section{Insert Figure 3}

Patients evaluated their access to knowledge from nurses and physicians as, on average, $3.38( \pm$ 0.59) (on a scale from 1-4) after two weeks and this evaluation remained consistent throughout the year (Table 2 Appendix 1 ). Over $80 \%$ of patients reported good access in all items of the AKS questionnaire except for the item "my family was kept updated all the time about matters concerning my care" where around $50 \%$ of patients agreed or very much agreed with that statement.

Six months after the procedure, over $25 \%$ of patients still had unanswered questions or concerns regarding their treatment and responded that they would have liked more information before the procedure (Figure 4).

\section{Insert Figure 4}

\subsection{Patient satisfaction}

Patients reported high satisfaction with the whole process in general. However, the hospital stay had not been as expected for $11 \%$ of patients and nearly $10 \%$ were dissatisfied the effect of the 
CRT treatment on their health in the first six months. Patients' satisfaction with care, measured with PSS, was high ( $3.44 \pm 0.56$ on a scale $1-4$, after two weeks), consistent over the whole year (Table 2 Appendix 1) and correlated with the fulfillment of knowledge expectations ( $\mathrm{r} 0.481$, $\mathrm{p}<0.001$ at six months). Over $90 \%$ of patients responded that they were satisfied or very satisfied for every item of the questionnaire except for how the nurses had prepared their family for their discharge where $71 \%$ were satisfied when asked after two weeks. Patients also reported high satisfaction with the support they received from healthcare professionals (39\% reported very good support) and their family and friends.

\subsection{Predictors of the fulfillment of knowledge expectations}

The effect of access to knowledge from nurses and physicians during hospitalization was independently associated with fulfillment of knowledge expectations. The better the access patients had to knowledge, the more knowledge they reported having received $(p<0.001)$.

The higher the expectations patients had, the less knowledge they reported having received $(p<0.001)$. The effect of educational level was also significant $(p<0.05)$ : the better educated patients reported receiving less knowledge than those with less education. The results from the mixed model analysis are presented in Table $3 z$.

Insert Table 3 z 


\section{Discussion and conclusions}

\subsection{Discussion}

This is both the first study presenting the patient educational aspect of CRT device treatment and, to our knowledge, the first follow-up study describing the patient's perspective of patient education after one year. The results are in concordance with previous studies from other noncardiac patient populations on the fulfillment of knowledge expectations [13,14,29], showing that patients with HF undergoing CRT device treatment expect more knowledge than they receive in all dimensions of empowering knowledge. In addition, we found that their reporting was consistent with follow-up questionnaires after two weeks, six months and one year. On average, $83 \%$ of patients had unfulfilled knowledge expectations. The results also indicate that the CRT patient population which may be perceived as having a "minor" invasive surgical procedure have similar educational needs as other surgical patients, both ambulatory orthopedic patients [12] and those having more invasive surgery, for example arthroplasty [14,25] or other surgery [13].

While the patients' needs for knowledge about their condition and treatment (the biophysiological dimension) and the functional implications of the CRT treatment were best fulfilled, the patients' least fulfilled knowledge expectations concerned the experiential dimension, which reflects emotional or psychological aspects of the treatment. This is of concern as $68 \%$ of the participants in this study received a CRT device with a defibrillator, and it is well known that living with the risk of receiving a shock can cause anxiety [30], especially during the first year post-implant [31].

Patients' fulfillment of their knowledge expectations did not change over time and even though almost all of them had been to the heart clinic for a follow-up, a substantial group (25-30\%) still had concerns and unanswered questions when asked six months after the procedure. This indicates that it is important to intervene with education early and ensure that the individual, educational needs as defined by the patients themselves, at every patient encounter, are addressed. Choosing the appropriate educational strategies and education material is an important component of promoting the learning process of patients. Systematic reviews of 
effective teaching on outcomes in both surgical patients [19] and patients with HF [32] indicate that the most effective means of delivering such patient education is through individualizing the content. This individualizing education can be performed by using combined mediums for delivery, providing the education on a one-on-one basis and in multiple sessions. Still patient education remains informal in patient care [33] and most common methods within hospital care are face-to-face education supplemented with printed, written information while more novel approaches using information technology in the form of interactive websites or web-based applications are less used [34,35].

We also demonstrated that patients rely heavily on healthcare professionals as an information source. Access to knowledge from nurses and doctors in the hospital was the strongest predictor of fulfillment of knowledge expectations, similar to what was found among patients undergoing arthroplasty [36]. Also, almost all patients reported having received information from the heart clinic healthcare professionals, presumably oral information. Face-to-face education is important, much appreciated and preferred by patients [37]. However, its effectiveness depends on multiple factors related to both patients and healthcare professionals [38] and it is not recognized to be effective on its own [34]. It should therefore be used in conjunction with other methods such as written material [34].

Not all patients had received written information as could be expected. Before the CRT device implantation, only $50 \%$ of patients reported having received written information about the procedure and around $25 \%$ of patients stated they had received no information at all from brochures throughout the one-year follow-up. Since the CRT treatment has been available for a long time, all manufacturers have by now produced specific brochures. It would have been expected that at least this educational material would have been available to patients if hospital publications in patients' own language were not available. It is therefore of concern if patients did not receive any written material or that they had forgotten receiving such material. Without any additional education, except the oral information, one can argue that the possibility of obtaining informed consent in a rather complex decision-making procedure is at risk of being hampered. 
Patient organizations were not an information source for the participants in this study and only around $20 \%$ had searched the Internet for information. This is interesting because patients are known to use the Internet for information but have also reported that support, recommendations and guidance from healthcare professionals are important to them when they access the plethora of information available on the Internet [37]. E-health technology can be an effective teaching strategy to improve the knowledge of patients and their satisfaction, and it can reduce anxiety [34] as long as such technology has a proper design, implementation and integration process [39]. A recent study on 27 websites in Sweden with information for cardiac patients demonstrated that most of them provided insufficient content, learning simulation and motivation for patients [40]. It may therefore be time to implement high quality web-based patient education for patients with HF who receive CRT, such as the website heartfailurematters.org of the Heart Failure Association of the European Society of Cardiology (ESC) that is recently available.

No demographic or clinical variables were clearly significant to fulfillment of knowledge expectations except that higher educated patients reported less fulfillment than those with less education. This is a further confirmation of the importance of individualizing the education, which has previously been emphasized in the literature [18,19,32], and of tailoring it to the patients" self-identified information needs [6] as these may vary and be multidimensional according to the theoretical perspective of empowering patient education [11]. In order to improve patient education in general, both patients and healthcare professionals need to be provided with skills training, including self-care for patients and educational interventions for healthcare professionals [9]. While this study shows the importance of face-to-face encounters in fulfilling knowledge expectations, that approach is under threat because of healthcare professionals' time restraints [38]. It is therefore of paramount importance that future interventions to facilitate patient education ensure good science-practice fit [9] and that healthcare professionals make strategic use of the limited time they have for patient education and shared decision-making.

One available approach for healthcare professionals to choose from is the Gothenburg personcentered care model (gPCC model) [21]. Previous studies have shown several benefits for patients with HF when this approach has been used [41-43] and the model seems to be robust 
and sustainable over time [44]. It is built on three cornerstones and starts with the patient's narrative to initiate the partnership between patient and healthcare professional. Thereafter, the patient and the professional discuss the care and co-create a health plan, which is finally documented in the patient's medical record and shared between the patient and the healthcare professionals. The focus is on patients' own goals, instead of the traditional behavioral changes that healthcare aims for, resulting in benefits for the patients. Jansson [45] found that patients identified their own goals, capacities, and resources to reach their goals, for example returning to work and maintaining social relations, and requested support in the form of coaching from healthcare professionals. Studies in person-centered care have shown that patients' self-efficacy could be strengthened when working within a person-centered approach [46,47], and patients with HF reported less uncertainty in illness (Dudas et al., 2013). Moreover, the discharge process in hospital has been reported as improved by patients with HF (; Ulin et al., 2014). Patients with low educational level have been found to benefit most from person-centered care by being involved in care decisions [48]. In addition, the healthcare sector has been reported as saving resources in the form of shorter length of hospital stay and reduced costs $[41,49]$.

\subsection{Limitations}

This study confirms comparable results from previous studies which used the same instruments on knowledge expectations and received knowledge in different populations of surgical patients, and adds to the growing evidence that patients have high knowledge expectations that are insufficiently fulfilled. However, interpretability of the results are lacking, i.e. to establish what changes in outcomes are meaningful [50] and identifying the minimum important difference in fulfillment of knowledge expectations that has some clinical significance.

This study had an acceptable response rate, with $76 \%(\mathrm{n}=133)$ of eligible patients $(\mathrm{N}=175)$ agreeing to participate in the study. The characteristics of patients who declined were comparable to the included patients in terms of age and gender. Still, a longitudinal study is challenged by its design in maintaining high levels of participation, and can yield biased assessments of the participant characteristics under investigation. We had a study coordinator sending out the questionnaires in due time at every time point (before surgery, after two weeks and six and 12 months), and that also gave a reminder after two weeks if the questionnaire had 
not been returned. Despite this, we had some drop-outs at every time point, ending up with $68 \%$ $(\mathrm{n}=90)$ of the participants completing the study at 12 months.

\subsection{Z Conclusions}

Patients undergoing CRT therapy device implantation receive less knowledge than they expect, and individual factors and the quality of face-to-face communication with healthcare professionals is related to their experience. Face-to-face is the most common method of delivering education, and healthcare professionals could consider implementing more diverse methods and materials in their educational practices.

\subsection{Practice implications}

The results of this study indicate the need for an early individual assessment of patients' knowledge and expectations for knowledge in order for healthcare professionals to address any ambiguity and tailoring the education to patients' self-defined needs. While the quality of faceto-face communication seems to be of utmost important to patients and affecting the fulfilment of their knowledge expectations it is concerning that not all patients received written educational material as it is well known that face-to-face approach is not effective for learning on its own. Healthcare professionals should consider implementing more diversity in their educational practices and these need to be streamlined to the needs of the individual and their family. Introducing suitable websites and providing written material to all patients could be a part of such a diversity. 


\section{Acknowledgments}

We gratefully acknowledge the assistance of the following: Kristjan Norland, MSc for statistical assistance, Árún K. Sigurdardottir, professor at the University of Akureyri, the nurses at the participating hospitals for their assistance with data collection, Anneli U. Hermansson, research nurse, for coordinating the study and Anchor English Proofreading Services for editing the manuscript. Our thanks go also to all the patients who participated in the study. 
Patients are expecting to learn more

\section{References}

[1] P. Ponikowski, K. Al Habib, M. Cowie, T. Force, S. Hu, T. Jaarsma, et al., Heart failure: Preventing disease and death worldwide, European Society of Cardiology, 2014.

[2] C.M. Alpert, M.A. Smith, S.L. Hummel, E.K. Hummel, Symptom burden in heart failure: assessment, impact on outcomes, and management, Heart Fail. Rev. (2017). doi:10.1007/s10741-016-9581-4.

[3] M. Brignole, A. Auricchio, G. Baron-Esquivias, P. Bordachar, G. Boriani, O.A. Breithardt, et al., 2013 ESC guidelines on cardiac pacing and cardiac resynchronization therapy: the task force on cardiac pacing and resynchronization therapy of the European Society of Cardiology (ESC). Developed in collaboration with the European Heart Rhythm Association, Europace. 15 (2013) 1070-1118. doi:10.1093/europace/eut206; 10.1093/europace/eut206.

[4] F. Fang, Z.Y. Jie, L.X. Xia, L. Ming, M. Zhan, G.S. Fen, et al., Cardiac Resynchronisation Therapy and Heart Failure: Persepctive from 5P Medicine, Card. Fail. Rev. 1 (2015) 35. doi:10.15420/cfr.2015.01.01.35.

[5] International Council of Nurses, The ICN code of ethics for nurses, (2012). http://www.icn.ch/images/stories/documents/about/icncode_english.pdf.

[6] International Council of Nurses, Position statement: Informed patients, (2008). http://www.icn.ch/images/stories/documents/publications/position_statements/E06_Infor med_Patients.pdf.

[7] Patients Rights Iceland, Act 74/1997, (1997). http://eng.velferdarraduneyti.is/acts-ofParliament/nr/20100.

[8] Health and Medical Services Sweden, Act 1982:763, (1982). http://notisum.se/rnp/sls/lag/19820763.HTM.

[9] C. Hoving, A. Visser, P.D. Mullen, B. van den Borne, A history of patient education by health professionals in Europe and North America: from authority to shared decision making education, Patient Educ. Couns. 78 (2010) 275-281. 
doi:10.1016/j.pec.2010.01.015.

[10] European Patients Forum, The European Patients' Forum Annual Work Plan 2015, http://www (n.d.). http://www.eu-patient.eu/globalassets/library/annual-work-plan/epf2015-annual-work-plan.pdf.

[11] H. Leino-Kilpi, K. Johansson, K. Heikkinen, A. Kaljonen, H. Virtanen, S. Salantera, Patient education and health-related quality of life: surgical hospital patients as a case in point, J. Nurs. Care Qual. 20 (2005) 307-308.

[12] K. Heikkinen, H. Leino-Kilpi, A. Hiltunen, K. Johansson, A. Kaljonen, S. Rankinen, et al., Ambulatory orthopaedic surgery patients' knowledge expectations and perceptions of received knowledge, J. Adv. Nurs. 60 (2007) 270-278. doi:10.1111/j.13652648.2007.04408.x.

[13] S. Rankinen, S. Salantera, K. Heikkinen, K. Johansson, A. Kaljonen, H. Virtanen, et al., Expectations and received knowledge by surgical patients, Int. J. Qual. Heal. Care. 19 (2007) 113-119. doi:10.1093/intqhe/mzl075.

[14] S. Klemetti, H. Leino-Kilpi, E. Cabrera, P. Copanitsanou, B. Ingadottir, N. Istomina, et al., Difference Between Received and Expected Knowledge of Patients Undergoing Knee or Hip Replacement in Seven European Countries, Clin. Nurs. Res. 24 (2014) 624-643. doi:10.1177/1054773814549992.

[15] S.M. Halbach, N. Ernstmann, C. Kowalski, H. Pfaff, T.-K. Pförtner, S. Wesselmann, et al., Unmet information needs and limited health literacy in newly diagnosed breast cancer patients over the course of cancer treatment, Patient Educ. Couns. (2016). doi:10.1016/j.pec.2016.06.028.

[16] R. Suhonen, H. Leino-Kilpi, Adult surgical patients and the information provided to them by nurses: a literature review, Patient Educ. Couns. 61 (2006) 5-15. doi:10.1016/j.pec.2005.02.012.

[17] K. Bolse, I. Johansson, A. Stromberg, Organisation of care for Swedish patients with an implantable cardioverter defibrillator, a national survey, J. Clin. Nurs. 20 (2011) 2600- 
2608. doi:10.1111/j.1365-2702.2010.03540.x; 10.1111/j.1365-2702.2010.03540.x.

[18] S. Fredericks, T. Yau, Clinical effectiveness of individual patient education in heart surgery patients: A systematic review and meta-analysis, Int. J. Nurs. Stud. 65 (2017) 4453. doi:10.1016/j.ijnurstu.2016.11.001.

[19] S. Fredericks, S. Guruge, S. Sidani, T. Wan, Postoperative patient education: A systematic review, Clin. Nurs. Res. 19 (2010) 144-164. doi:10.1177/1054773810365994.

[20] S. Barnason, C. White-Williams, L.P. Rossi, M. Centeno, D.L. Crabbe, K.S. Lee, et al., Evidence for Therapeutic Patient Education Interventions to Promote Cardiovascular Patient Self-Management: A Scientific Statement for Healthcare Professionals from the American Heart Association, Circ. Cardiovasc. Qual. Outcomes. 10 (2017) 1-23. doi:10.1161/HCQ.0000000000000025.

[21] I. Ekman, K. Swedberg, C. Taft, A. Lindseth, A. Norberg, E. Brink, et al., Person-centered care--ready for prime time, Eur. J. Cardiovasc. Nurs. 10 (2011) 248-251. doi:10.1016/j.ejcnurse.2011.06.008; 10.1016/j.ejcnurse.2011.06.008.

[22] L.A. Allen, L.W. Stevenson, K.L. Grady, N.E. Goldstein, D.D. Matlock, R.M. Arnold, et al., Decision Making in Advanced Heart Failure: A Scientific Statement From the American Heart Association, Circ. . 125 (2012) 1928-1952. doi:10.1161/CIR.0b013e31824f2173.

[23] H. Leino-Kilpi, J. Vuorenheimo, The patient's perspective on nursing quality: developing a framework for evaluation, Int. J. Qual. Health Care. 6 (1994) 85-95.

[24] R. Suhonen, E. Papastavrou, G. Efstathiou, H. Tsangari, D. Jarosova, H. Leino-Kilpi, et al., Patient satisfaction as an outcome of individualised nursing care, Scand. J. Caring Sci. 26 (2012) 372-380. doi:10.1111/j.1471-6712.2011.00943.x; 10.1111/j.14716712.2011.00943.x.

[25] Å. Johansson Stark, B. Ingadottir, S. Salanterä, A. Sigurdardottir, K. Valkeapää, M. Bachrach-Lindström, et al., Fulfilment of knowledge expectations and emotional state among people undergoing hip replacement: A multi-national survey, Int. J. Nurs. Stud. 51 
(2014) 1491-1499. doi:10.1016/j.ijnurstu.2014.03.006.

[26] Å. Johansson Stark, A. Charalambous, N. Istomina, S. Salanterä, A.K. Sigurdardottir, P. Sourtzi, et al., The quality of recovery on discharge from hospital, a comparison between patients undergoing hip and knee replacement - a European study, J. Clin. Nurs. (2016). doi:10.1111/jocn.13278.

[27] M.R. Benedictus, A.E. Leeuwis, M.A.A. Binnewijzend, J.P.A. Kuijer, P. Scheltens, F. Barkhof, et al., Lower cerebral blood flow is associated with faster cognitive decline in Alzheimer's disease, Eur. Radiol. 27 (2017) 1169-1175. doi:10.1007/s00330-016-4450-z.

[28] World Medical Association, World Medical Association Declaration of Helsinki: ethical principles for medical research involving human subjects, Jama. 310 (2013) 2191-2194. doi:10.1001/jama.2013.281053 [doi].

[29] A.M. Ryhanen, S. Rankinen, M. Siekkinen, M. Saarinen, H. Korvenranta, H. Leino-Kilpi, The impact of an empowering Internet-based Breast Cancer Patient Pathway programme on breast cancer patients' knowledge: a randomised control trial, Patient Educ. Couns. 88 (2012) 224-231. doi:10.1016/j.pec.2012.02.013; 10.1016/j.pec.2012.02.013.

[30] I. Thylén, R.L. Dekker, T. Jaarsma, A. Strömberg, D.K. Moser, Characteristics associated with anxiety, depressive symptoms, and quality-of-life in a large cohort of implantable cardioverter defibrillator recipients, J. Psychosom. Res. (2014). doi:10.1016/j.jpsychores.2014.05.007.

[31] G. Magyar-Russell, B.D. Thombs, J.X. Cai, T. Baveja, E.A. Kuhl, P.P. Singh, et al., The prevalence of anxiety and depression in adults with implantable cardioverter defibrillators: A systematic review, J. Psychosom. Res. (2011). doi:10.1016/j.jpsychores.2011.02.014.

[32] S. Fredericks, H. Beanlands, K. Spalding, M. Da Silva, Effects of the characteristics of teaching on the outcomes of heart failure patient education interventions: a systematic review, Eur. J. Cardiovasc. Nurs. 9 (2010) 30-37. doi:10.1016/j.ejcnurse.2009.08.002 [doi].

[33] P.J. Dunn, K.L. Milheim, Enhancing informal patient education in nursing practice: A 
review of literature, J. Nurs. Educ. Pract. 7 (2016) 18-24. doi:10.5430/jnep.v7n2p18.

[34] A.J. Friedman, R. Cosby, S. Boyko, J. Hatton-Bauer, G. Turnbull, Effective teaching strategies and methods of delivery for patient education: A systematic review and practice guideline recommendations, J. Cancer Educ. 26 (2011) 12-21.

http://www.scopus.com/inward/record.url?eid=2-s2.0-

79959519814\&partnerID=40\&md5=e771a62784b33dd3ccdb019da9f54036.

[35] S. Klemetti, B. Ingadottir, J. Katajisto, C. Lemonidou, E. Papastavrou, K. Valkeapää, et al., Skills and Practices of European Orthopedic Nurses in Empowering Patient Education, Res. Theory Nurs. Pract. 32 (2018) 382-399. doi:10.1891/1541-6577.32.4.382.

[36] B. Ingadottir, A. Johansson Stark, H. Leino-Kilpi, A.K. Sigurdardottir, K. Valkeapää, M. Unosson, The fulfilment of knowledge expectations during the perioperative period of patients undergoing knee arthroplasty - a Nordic perspective, J. Clin. Nurs. 23 (2014). doi:10.1111/jocn.12552.

[37] B. Ingadottir, K. Blondal, T. Jaarsma, I. Thylen, Perceptions about traditional and novel methods to learn about post-operative pain management - a qualitative study, J. Adv. Nurs. Epub ahead (2016). doi:10.1111/jan.13021.

[38] C. Marcus, Strategies for improving the quality of verbal patient and family education: a review of the literature and creation of the EDUCATE model, Heal. Psychol. Behav. Med. 2 (2014) 482-495. doi:10.1080/21642850.2014.900450.

[39] M.P. Fox, A systematic review of the literature reporting on studies that examined the impact of interactive, computer-based patient education programs, Patient Educ. Couns. 77 (2009) 6-13. doi:DOI: 10.1016/j.pec.2009.02.011.

[40] L. Klompstra, M. Johansson Östbring, T. Jaarsma, S. Ågren, B. Fridlund, C. Hjelm, et al., The appropriateness and presentation of commonly available cardiovascular web-pages in the Swedish language, Comput. Inform. Nurs. 37 (2019) in press.

[41] I. Ekman, A. Wolf, L.E. Olsson, C. Taft, K. Dudas, M. Schaufelberger, et al., Effects of person-centred care in patients with chronic heart failure: the PCC-HF study, Eur. Heart J. 
33 (2012) 1112-1119. doi:10.1093/eurheartj/ehr306; 10.1093/eurheartj/ehr306.

[42] K. Ulin, L.E. Olsson, A. Wolf, I. Ekman, Person-centred care - An approach that improves the discharge process, Eur. J. Cardiovasc. Nurs. (2014). doi:10.1177/1474515115569945.

[43] K. Dudas, L.E. Olsson, A. Wolf, K. Swedberg, C. Taft, M. Schaufelberger, et al., Uncertainty in illness among patients with chronic heart failure is less in person-centred care than in usual care, Eur. J. Cardiovasc. Nurs. 12 (2013) 521-528. doi:10.1177/1474515112472270.

[44] A. Fors, K. Swedberg, K. Ulin, A. Wolf, I. Ekman, Effects of person-centred care after an event of acute coronary syndrome: Two-year follow-up of a randomised controlled trial, Int. J. Cardiol. (2017). doi:10.1016/j.ijcard.2017.08.069.

[45] I. Jansson, A. Fors, I. Ekman, K. Ulin, Documentation of person-centred health plans for patients with acute coronary syndrome, Eur. J. Cardiovasc. Nurs. (2018). doi:10.1177/1474515117718415.

[46] A. Fors, C. Taft, K. Ulin, I. Ekman, Person-centred care improves self-efficacy to control symptoms after acute coronary syndrome: A randomized controlled trial, Eur. J. Cardiovasc. Nurs. (2016). doi:10.1177/1474515115623437.

[47] A. Wolf, A. Fors, K. Ulin, J. Thorn, K. Swedberg, I. Ekman, An eHealth diary and symptom-tracking tool combined with person-centered care for improving self-efficacy after a diagnosis of acute coronary syndrome: A substudy of a randomized controlled trial, J. Med. Internet Res. (2016). doi:10.2196/jmir.4890.

[48] A. Wolf, R. Vella, A. Fors, The impact of person-centred care on patients' care experiences in relation to educational level after acute coronary syndrome: secondary outcome analysis of a randomised controlled trial, Eur. J. Cardiovasc. Nurs. (2019). doi:10.1177/1474515118821242.

[49] E. Hansson, I. Ekman, K. Swedberg, A. Wolf, K. Dudas, L. Ehlers, et al., Person-centred care for patients with chronic heart failure - A cost-utility analysis, Eur. J. Cardiovasc. Nurs. (2014). doi:10.1177/1474515114567035. 
Patients are expecting to learn more

[50] L. McClimans, Interpretability, validity, and the minimum important difference, Theor. Med. Bioeth. 32 (2011) 389-401. doi:10.1007/s11017-011-9186-9. 


\section{Legends}

\section{Figure 1.}

Flowsheet of patient participation in the study

\section{Figure 2.}

The fulfillment of knowledge expectations (mean difference between expected (KEhp) and received (RKhp) knowledge) for the total scale and the six dimensions, at three different time points: at two weeks (T2), six months (T3) and 12 months (T4) after the CRT procedure. Negative value represents unfulfilled knowledge expectations.

\section{Figure 3.}

The sources of information patients used to acquire knowledge, asked before the procedure (T1), and two weeks (T2), six months (T3) and 12 months (T4) later. Footnote: HP, healthcare professionals.

\section{Figure 4.}

Proportion of patients at two weeks, six months and 12 months after the CRT procedure, who had unanswered questions or concerns regarding the treatment and would have liked more information before the procedure 


\section{Highlights}

- Patients undergoing device implantation have diverse educational needs

- Educational needs of patients with heart failure are similar to that of other surgical patients

- Patients' expectations for education are not being fulfilled

- Direct face-to-face education is of the utmost importance for patients 
Table 1. Baseline characteristics $(\mathrm{N}=133)$

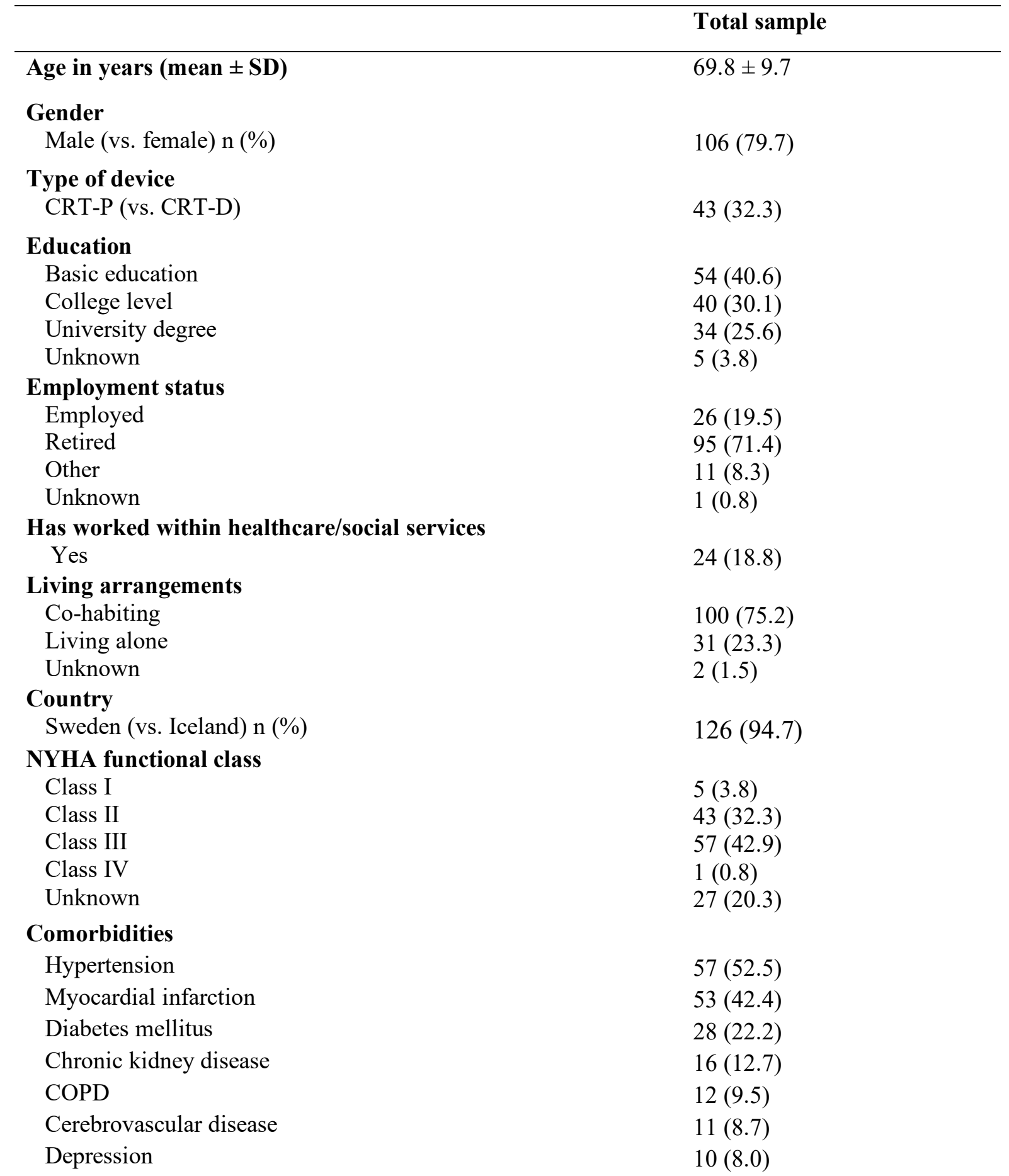

Variables are expressed as mean $\pm \mathrm{SD}$ or $\mathrm{n}(\%)$.

$\mathrm{SD}$, standard deviation; COPD, Chronic obstructive pulmonary disease;

${ }^{a}$ Self-reported by subjects. ${ }^{b}$ Higher scores mean better health.

${ }^{\mathrm{c}}$ Cardiac resynchronization therapy with pacemaker only (CRT-P) or with defibrillator function also (CRT-D). 


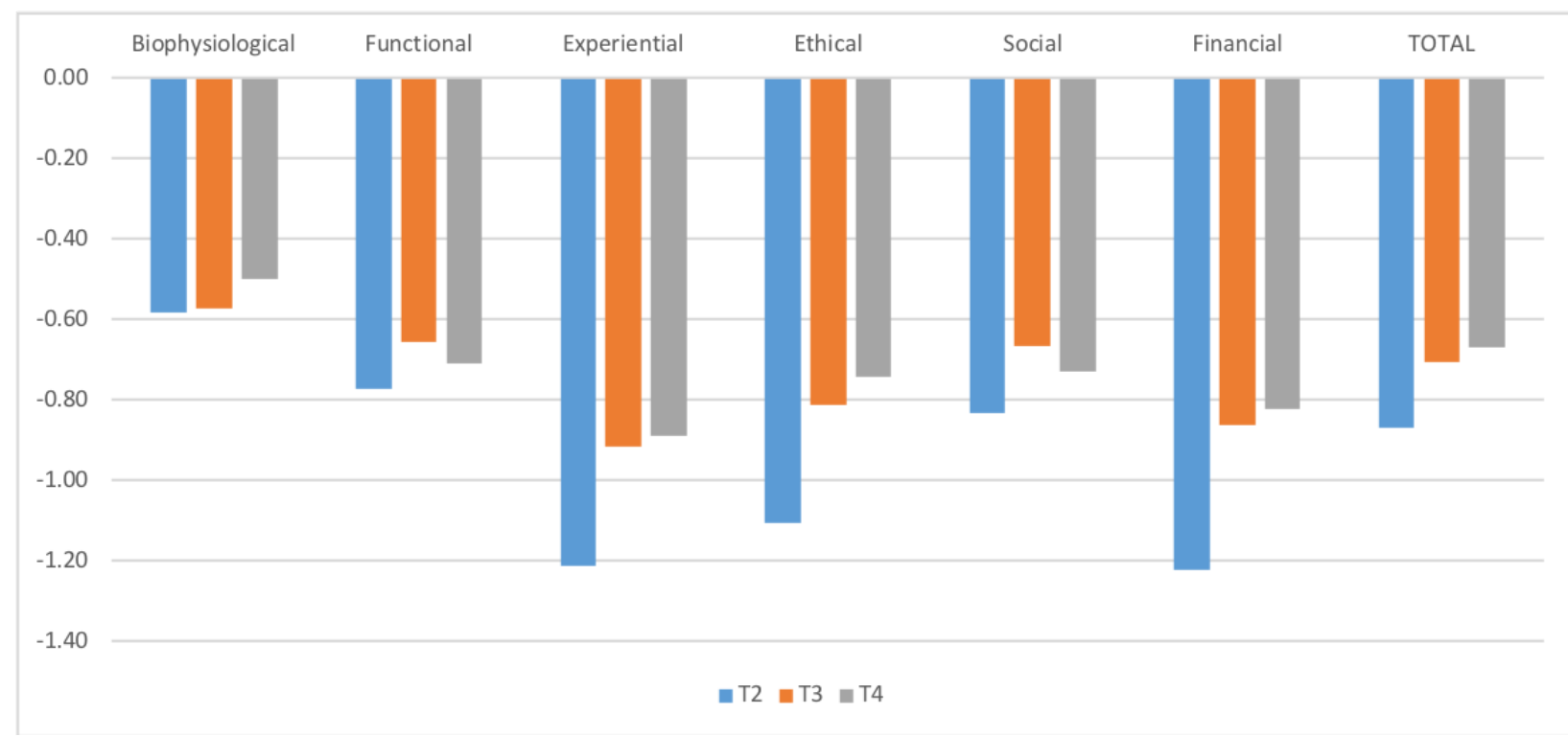

\section{Figure 1}

The fulfillment of knowledge expectations (mean difference between expected (KEhp) and received (RKhp) knowledge) for the total scale and the six dimensions, at three different time points: at two weeks (T2), six months (T3) and 12 months (T4) after the CRT procedure. Negative value represents unfulfilled knowledge expectations. 


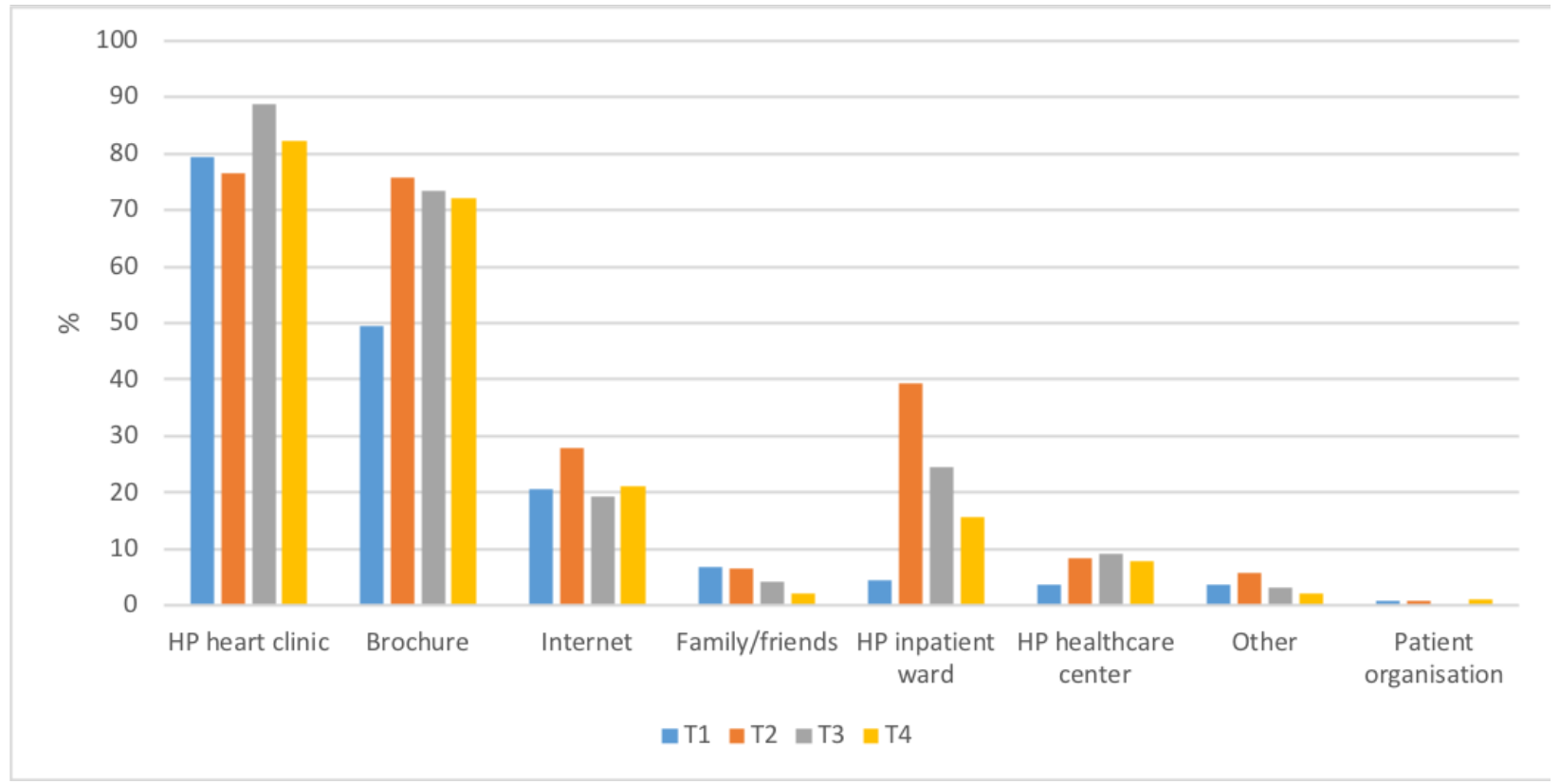

Figure 2 The sources of information patients used to acquire knowledge, asked before the procedure (T1), and two weeks (T2), six months (T3) and 12 months (T4) later. HP, healthcare professionals. 
Patients are expecting to learn more

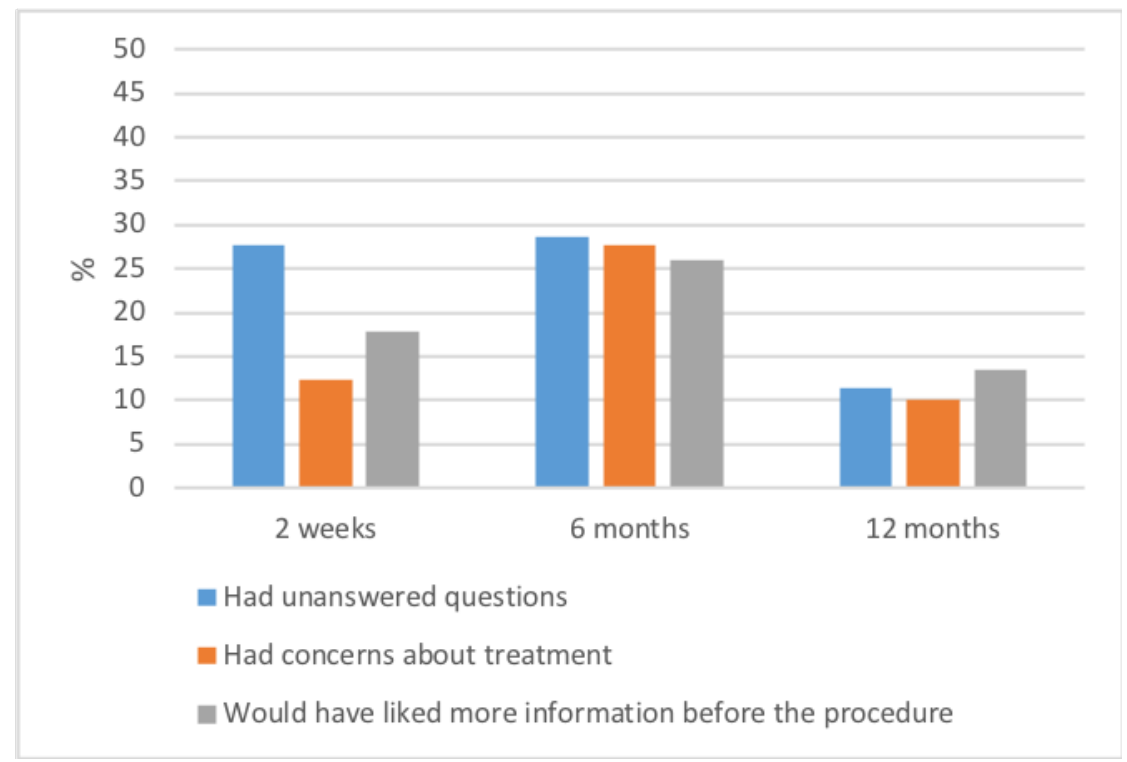

\section{Figure 3}

Proportion of patients at two weeks, six months and 12 months after the CRT procedure, who had unanswered questions or concerns regarding the treatment and would have liked more information before the procedure 


\section{Table 2}

The results from the mixed model linear analysis on effect of covariates on fulfillment of knowledge expectations over 12 months from the CRT procedure

\begin{tabular}{|c|c|c|c|c|}
\hline Parameter & $\boldsymbol{\beta}$ & Lower 95 CI & Upper 95 CI & SE \\
\hline Intercept & -0.17 & -1.600 & 1.300 & 0.79 \\
\hline Age & 0.00 & -0.015 & 0.014 & 0.01 \\
\hline Sex & -0.16 & -0.450 & 0.130 & 0.16 \\
\hline Educational level & -0.30 & -0.520 & -0.069 & $0.12 *$ \\
\hline $\begin{array}{l}\text { Employed within } \\
\text { healthcare/social services }\end{array}$ & 0.01 & -0.260 & 0.280 & 0.15 \\
\hline Cohabitation status & 0.14 & -0.140 & 0.410 & 0.15 \\
\hline CRT type & -0.15 & -0.440 & 0.130 & 0.16 \\
\hline Access to knowledge & 0.74 & 0.420 & 1.100 & $0.18^{* * *}$ \\
\hline Knowledge expectations & -1.03 & -1.300 & -0.800 & $0.13 * * *$ \\
\hline Patient satisfaction & 0.22 & -0.200 & 0.650 & 0.23 \\
\hline Time since implantation & 0.02 & 0.008 & 0.033 & $0.01 * *$ \\
\hline
\end{tabular}

Model: Code SD $=0.39$, Residual $\mathrm{SD}=0.41$

$* \mathrm{p}<0.05, * * \mathrm{p}<0.01, * * * \mathrm{p}<0.001$, SE standard error

CRT: Cardiac resynchronization therapy; Access to knowledge: mean value of total AKS scale; Knowledge expectations: mean value of KEhp total scale, Patient satisfaction: mean value of total PSS scale; SE standard error 
Patients are expecting to learn more

Supplement 1. Flowsheet of patient participation in the study

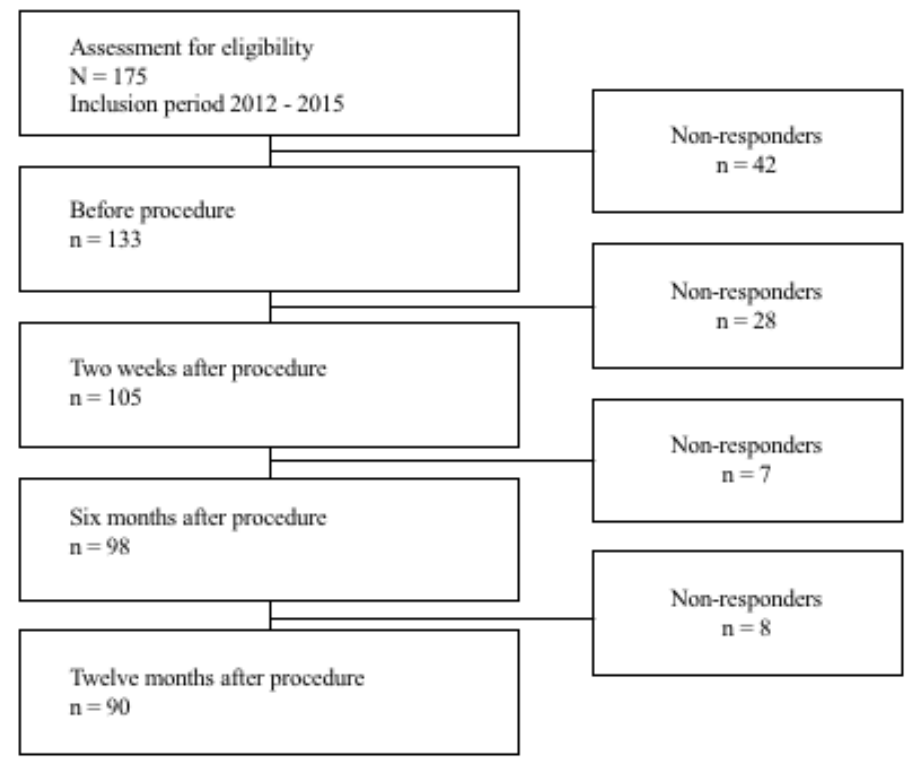


Supplement 2. Fulfillment of knowledge expectations, access to knowledge and patient satisfaction at two weeks, six months and one year after the CRT procedure.

\begin{tabular}{|c|c|c|c|c|c|c|c|}
\hline & $\mathrm{T} 1$ & $\mathrm{~T} 2$ & $\mathrm{~T} 3$ & $\mathrm{~T} 4$ & $\mathrm{~T} 1 / \mathrm{T} 2$ & $\mathrm{~T} 1 / \mathrm{T} 3$ & $\mathrm{~T} 1 / \mathrm{T} 4$ \\
\hline & $\mathrm{N}=133$ & $\mathrm{~N}=109$ & $\mathrm{~N}=98$ & $\mathrm{~N}=90$ & $\mathrm{~N}=108$ & $\mathrm{~N}=98$ & $\mathrm{~N}=90$ \\
\hline & $\mathrm{M}( \pm \mathrm{SD})$ & $\mathrm{M}( \pm \mathrm{SD})$ & $\mathrm{M}( \pm \mathrm{SD})$ & $\mathrm{M}( \pm \mathrm{SD})$ & $\mathrm{M}( \pm \mathrm{SD})$ & $\mathrm{M}( \pm \mathrm{SD})$ & $M( \pm \mathrm{SD})$ \\
\hline & KEhp & RKhp & RKhp & RKhp & $\begin{array}{l}\text { KEhp - } \\
\text { RKhp }_{\text {T2 }}\end{array}$ & $\begin{array}{l}\text { KEhp - } \\
\text { RKhp }_{\text {T3 }}\end{array}$ & $\begin{array}{l}\text { KEhp - } \\
\text { RKhp }_{\text {T4 }}\end{array}$ \\
\hline \multicolumn{8}{|l|}{$\begin{array}{l}\text { Dimension of } \\
\text { knowledge }\end{array}$} \\
\hline Bio-physiological & $3.83(0.36)$ & $3.26(0.67)$ & $3.27(0.58)$ & $3.33(0.54)$ & $-0.58(0.74)^{*}$ & $-0.57(0.63)^{*}$ & $-0.50(0.67)^{*}$ \\
\hline Functional & $3.63(0.51)$ & $2.88(0.77)$ & $2.97(0.70)$ & $2.93(0.71)$ & $-0.80(0.85)^{*}$ & $-0.69(0.79)^{*}$ & $-0.73(0.83)^{*}$ \\
\hline Experiential & $3.43(0.69)$ & $2.26(1.01)$ & $2.51(1.01)$ & $2.51(0.97)$ & $-1.21(1.22)^{*}$ & $-0.91(1.13)^{*}$ & $-0.89(1.14)^{*}$ \\
\hline Ethical & $3.46(0.56)$ & $2.36(1.00)$ & $2.64(0.92)$ & $2.72(0.85)$ & $-1.11(1.12)^{*}$ & $-0.81(1.02)^{*}$ & $-0.74(0.94) *$ \\
\hline Social & $3.30(0.61)$ & $2.50(0.94)$ & $2.64(0.95)$ & $2.60(0.83)$ & $-0.83(1.08)^{*}$ & $-0.67(1.02)^{*}$ & $-0.73(0.91)^{*}$ \\
\hline Financial & $3.31(0.76)$ & $2.10(1.05)$ & $2.43(1.07)$ & $2.41(1.03)$ & $-1.22(1.21)^{*}$ & $-0.86(1.11)^{*}$ & $-0.82(1.20)^{*}$ \\
\hline Total scale & $3.53(0.46)$ & $2.67(0.77)$ & $2.83(0.69)$ & $2.85(0.69)$ & $-0.87(0.87)^{*}$ & $-0.71(0.76)^{*}$ & $-0.67(0.79)^{*}$ \\
\hline AKS & & $3.38(0.59)$ & $3.40(0.56)$ & $3.46(0.47)$ & & & \\
\hline PSS & & $3.44(0.56)$ & $3.46(0.45)$ & $3.47(0.43)$ & & & \\
\hline
\end{tabular}

${ }^{*} \mathrm{p}<0.001$ paired t-test

KEhp Knowledge Expectations of hospitalized patients Scale; RKhp Received Knowledge of hospitalized patients scale; T1 Before CRT implantation; T2 two weeks after CRT; T3 six months after CRT; T4 one year after CRT; AKS Access to Knowledge Scale; PSS Patient Satisfaction Scale 